\title{
Type 2 leprosy reaction with Sweet's syndrome-like presentation*
}

\author{
Francielle Chiavelli Chiaratti ${ }^{1}$ \\ Antonielle Borges Faria Neumann ${ }^{1}$
}

\author{
Egon Luiz Rodrigues Daxbacher ${ }^{1}$ \\ Thiago Jeunon ${ }^{1}$
}

DOI: http:/ / dx.doi.org/10.1590/abd1806-4841.20164111

\begin{abstract}
Leprosy is a chronic disease characterized by manifestations in the peripheral nerves and skin. The course of the disease may be interrupted by acute phenomena called reactions. This article reports a peculiar case of type 2 leprosy reaction with Sweet's syndrome-like features as the first clinical manifestation of leprosy, resulting in a delay in the diagnosis due to unusual clinical presentation. The patient had clinical and histopathological features reminiscent of Sweet's syndrome associated with clusters of vacuolated histiocytes containing acid-fast bacilli isolated or forming globi. Herein, it is discussed how to recognize type 2 leprosy reaction with Sweet's syndrome features, the differential diagnosis with type 1 leprosy reaction and the treatment options. When this kind of reaction is the first clinical presentation of leprosy, the correct diagnosis might be not suspected clinically, and established only with histopathologic evaluation.
\end{abstract}

Keywords: Leprosy; Leprosy, multibacillary; Sweet syndrome

\section{INTRODUCTION}

Leprosy is a chronic, infectious disease caused by Mycobacterium leprae - acid fast bacilli (AFB) - and characterized by neural and cutaneous manifestations. The chronic course of the disease can be stopped by acute phenomena called reactions. Type 1 reactions occur in borderline patients and are due to variations in cellular immunity; type 2 reactions are mediated by immune complexes, occur in multibacillary patients and are characterized by diverse clinical manifestations, being stereotypical the erythema nodosum leprosum (ENL). Reactions usually appear during or after the treatment of leprosy, but they can also represent the first manifestation of the disease, making diagnosis more difficult. ${ }^{1}$

Sweet's syndrome, on the other hand, is an acute neutrophilic dermatosis characterized by painful erythematous edematous plaques, accompanied by fever, leukocytosis with neutrophilia and infiltrate rich in neutrophils in the dermis, associated with subepidermal edema of variable intensity. It may be idiopathic or associated with infections, inflammatory and autoimmune diseases, drugs, neoplasia and pregnancy. ${ }^{2}$

We report a peculiar case of type 2 leprosy reaction with Sweet's syndrome-like features as the first clinical manifestation of leprosy.

\section{CASE REPORT}

Female patient, 38 years old, residing in Rio de Janeiro, with a history of asthma, reported that, one year before the medical consultation, intermittent erythematous lesions on the lower members had appeared, which improved with the use of oral corticosteroids for asthma attacks. In the previous month, skin lesions became diffuse and associated with fever, 
myalgia, nausea and vomiting, without neurological symptoms. On examination, papules and erythematous edematous plaques were observed, some with a pseudo-vesicular aspect and others with central pallor, disseminated over the body, sparing mucosa, palms and soles (Figures 1, 2 and 3). Neurological examination presented no changes. Blood count showed 11,000 leukocytes with $90 \%$ neutrophils, and biochemical laboratory tests showed no changes. Histopathological examination of the skin revealed marked edema of the papillary dermis with infiltration of intact and fragmented neutrophils, in association with groups of vacuolized histiocytes in the reticular dermis, arranged along the neurovascular bundles. Fite's staining was positive (5+) for AFB (Figures 4, 5, 6 and $7)$. We concluded that this is a case of type 2 leprosy reaction with clinical and histopathological features reminiscent of Sweet's syndrome.

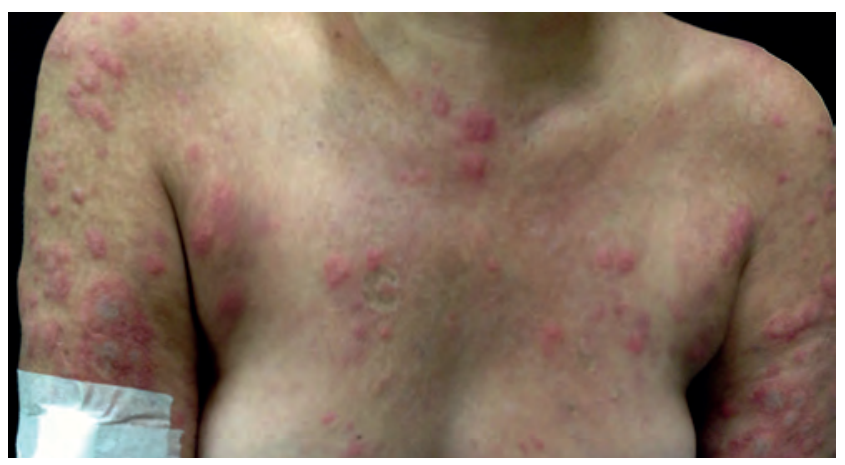

FIGURE 1: Patient with nodules, papules and erythematous edematous plaques, some with pseudo vesicles aspect and others with central pallor, affecting arms and chest

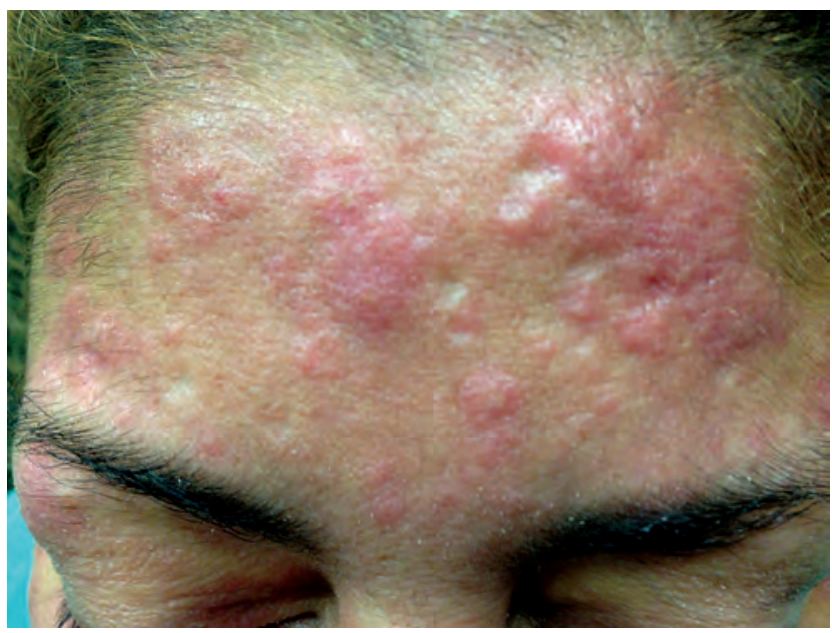

FIGURE 2: Papules and erythematous edematous plaques affecting the forehead

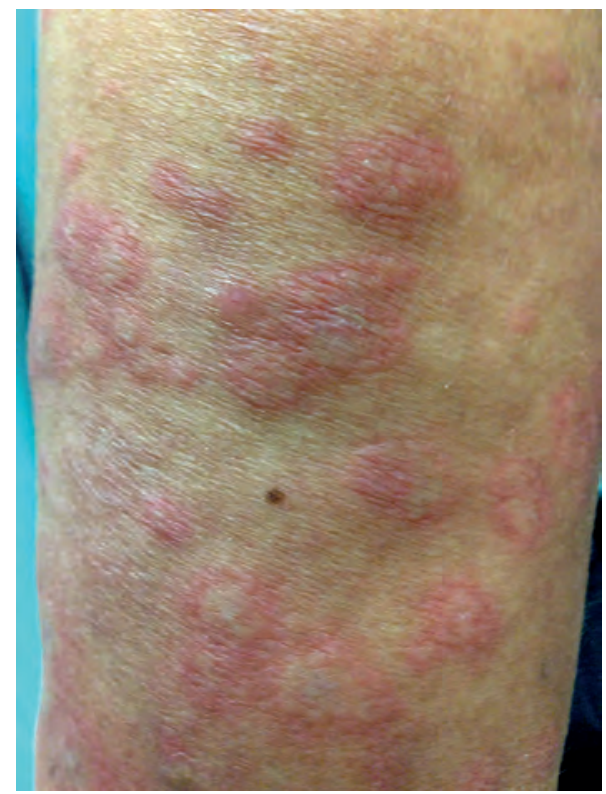

Figure 3:

Erythematous plaques with pale center and pseudo vesicle aspect on the right arm

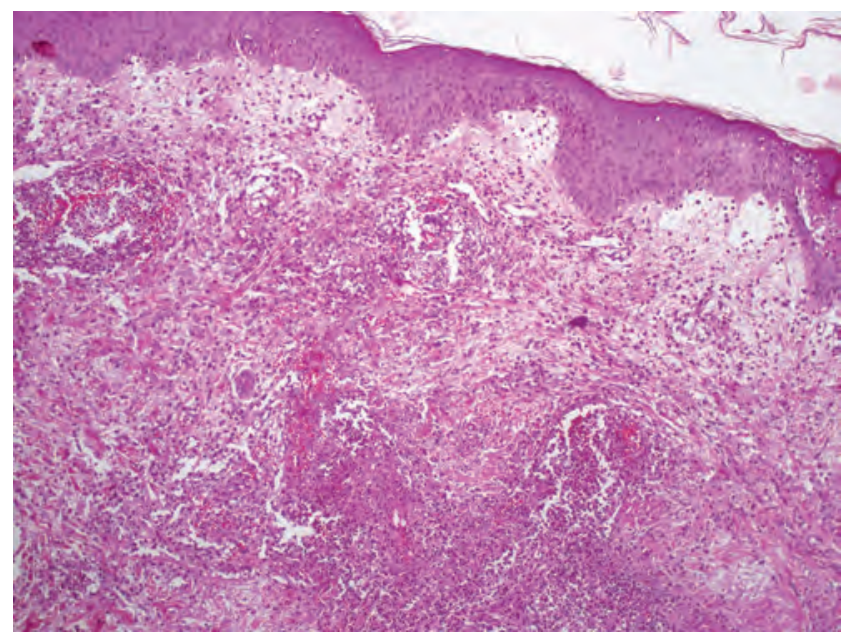

FIGURE 4: Histopathology showing marked edema of the papillary dermis with superficial and deep inflammatory infiltrate rich in neutrophils (hematoxylin and eosin, 100x)

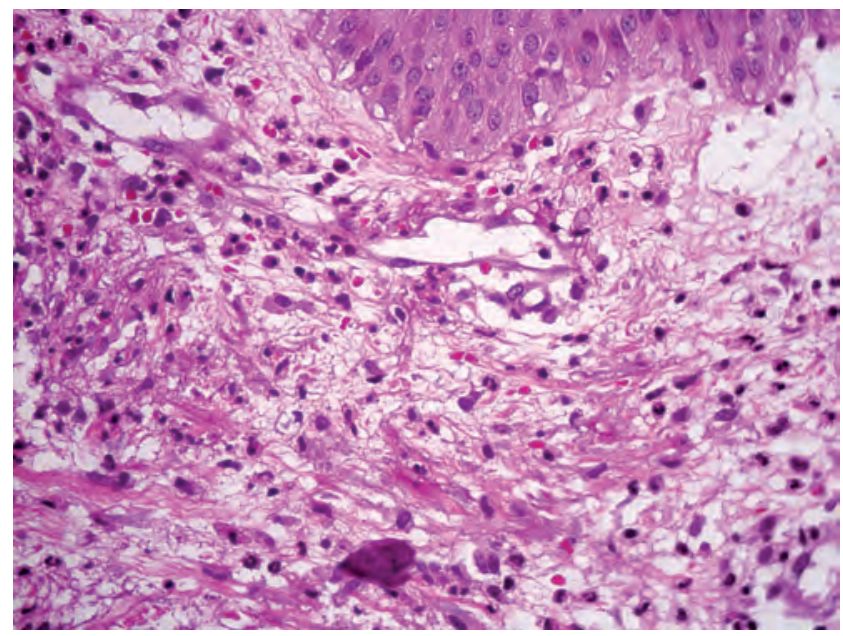

FIGURE 5: Infiltration of intact and fragmented neutrophils in the papillary dermis, and red blood cell extravasation (hematoxylin and eosin, 400x) 


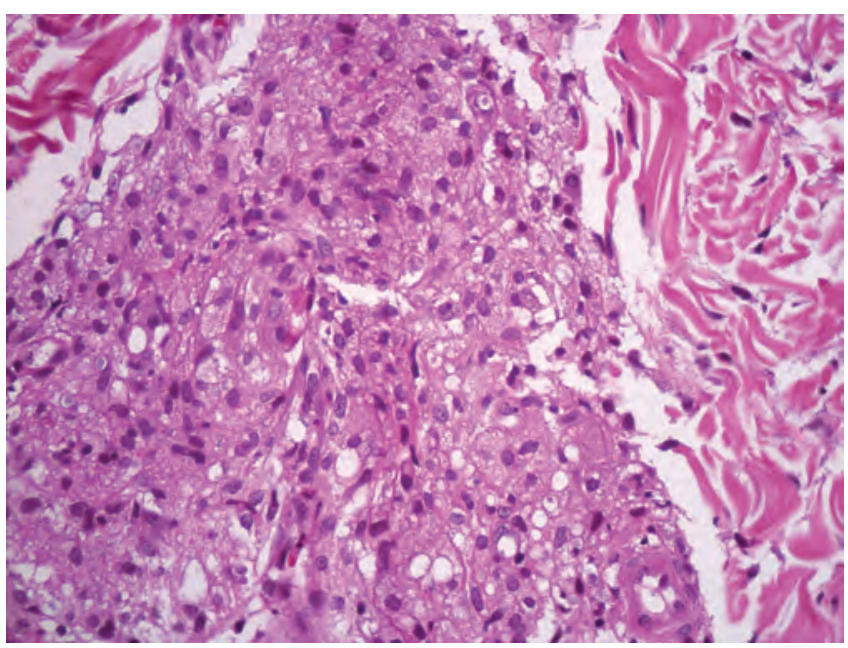

Figure 6: Deep nodular infiltrate, rich in vacuolated histiocytes (hematoxylin and eosin, 400x)

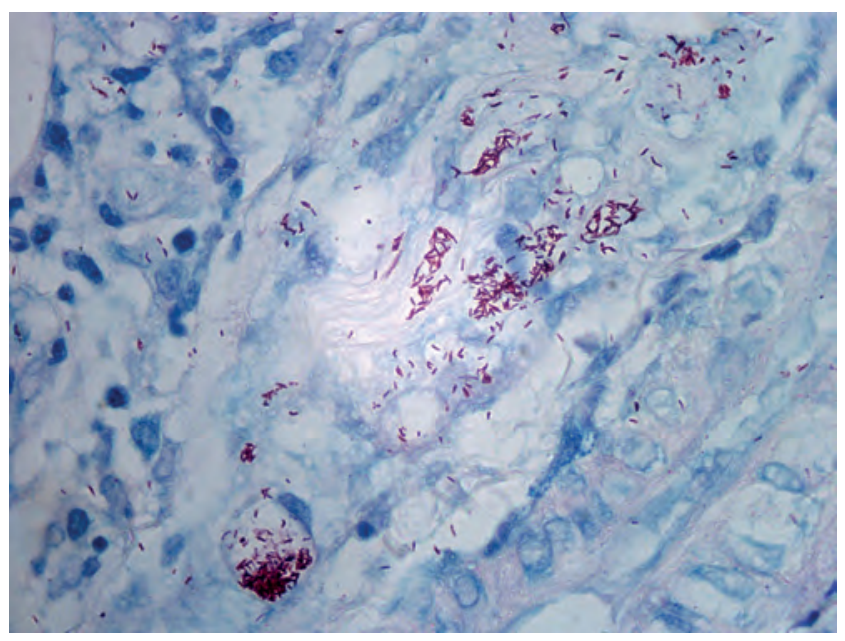

Figure 7: Numerous acid-fast bacilli(AFB), isolated or forming globi (Fite-Faraco, 400x)

The notification of the case was performed and the degree of disability and neural function was assessed, showing no changes (grade 0). Evaluation of household contacts (two children) did not present any signs or symptoms of leprosy, and they were referred to take the second dose of the "bacillus Calmette-Guerin" (BCG) vaccine. The patient treatment started with multibacillary multidrug therapy and oral prednisone at a dose of $1 \mathrm{mg} / \mathrm{kg} /$ day. Later, pentoxifylline at a dose of $400 \mathrm{mg}$ / day was associated, with gradual increase up to a dose of $400 \mathrm{mg}$ every 8 hours, in order to slowly reduce the corticosteroid until its complete withdrawal. The patient presented significant clinical improvement at the end of 2 months of treatment, but the lesions worsened during the weaning of oral prednisone. It was proposed starting thalidomide after insertion of intrauterine device and use of injectable contraceptives. Patient is maintained in outpatient follow-up.

\section{DISCUSSION}

Sweet's syndrome is an acute febrile neutrophilic dermatosis, first described in 1964 by Robert Douglas Sweet. ${ }^{3}$ Its characteristics are fever, neutrophilia and painful purplish erythematous plaques. These plaques may contain pseudo vesicles due to severe edema of the papillary dermis. With the evolution of the lesions, there may be a central clearing, resulting in target aspect similar to erythema multiforme. ${ }^{2}$ The most commonly affected sites are face, neck, chest, back and upper extremities. Histopathology is characterized by dense infiltrate of intact and fragmented neutrophils in the superficial and middle dermis and marked edema in the papillary skin layer. According to the etiology, the syndrome can be divided into 3 groups: classical (or idiopathic), associated with malignant disease and drug-induced. The classic form predominates in females and may be associated with inflammatory and autoimmune diseases, infections - the most common occurring in the gastrointestinal and upper respiratory tracts - and pregnancy. Most cases associated with cancer is due to acute myeloid leukemia. ${ }^{4}$

Leprosy reactions are acute immune inflammatory events affecting mainly skin and nerves. They are the main cause of nerve damage and disability caused by leprosy. They are classified into 2 major types: type 1 and type 2 . Type 1 reaction, or reversal reaction, occurs in borderline patients as a result of variations in cellular immunity. It is characterized by reactivation of preexisting lesions or by the appearance of new lesions, which are erythematous and infiltrated plaques with swollen appearance. It's possible to occur swelling of the extremities and neuritis, but, rarely, systemic manifestation. ${ }^{1,5}$ Type 2 reaction is mediated by immune complexes, occurring in multibacillary patients and presenting typically as ENL. This is characterized by inflammatory nodules, erythematous and painful, which can progress to necrosis. Often they are located on face and extremities and tend to bilateralism and symmetry. Type 2 reaction is often associated with general symptoms and can show systemic involvement, in particular in liver and kidney. ${ }^{1,5}$

There are atypical forms of type 2 reaction, called erythema multiforme-like and Sweet's syndrome-like reactions. Erythema multiforme-like is characterized by macule and purplish erithemous plaques, with formation of vesicles and blisters progressing to necrosis. Target lesions are typical. ${ }^{6,7}$ In non-typical cases, the condition may be confused with Sweet's syndrome-like reaction. 
Sweet's syndrome-like leprosy reaction was first described in 1987 by Kuo and Chan. ${ }^{8}$ The authors reported a case clinically suggestive of Sweet's syndrome, but with histopathological features of lepromatous leprosy, associated with edema of the papillary dermis and dense dermal neutrophilic infiltrate. Since then, few cases have been published. ${ }^{9-13}$ It is classified as a subtype of type 2 reaction and occurs more often in borderline-lepromatous patients. ${ }^{10}$

The clinical diagnosis of type 2 reaction variant is difficult when not exist nodular lesions characteristic of ENL, predominating lesions in edematous plaques that are frequently misinterpreted as a type 1 reaction.

Sweet's syndrome-like leprosy reaction is more easily recognized in patients with leprosy already diagnosed than in those without previous diagnosis of the baseline disease. ${ }^{10}$ In this case, the use of oral corticosteroids for asthma treatment resulted in partial and intermittent reversal of reaction feature and possibly contributed to the delay in the diagnosis. Although the patient did not present skin lesions and neurological changes suggestive of leprosy, chronic clinical setting and the presence of lesions similar to those of Sweet's syndrome disseminated over the body helped in diagnostic elucidation.

In the histopathological study of type 1 reaction, a large influx of lymphocytes and confluence of tuberculoid granuloma in the dermis are observed, which can be dissected by edema or show central fibrinoid necrosis. ${ }^{14}$ There may be also "blurring" of the dermoepidermal junction, a missing feature in the torpid forms of borderline leprosy.

Histopathology of classical type 2 leprosy reaction (ENL) is characterized by a large influx of neutrophils in the dermis, which is permeated by groups of vacuolated histiocytes containing bacilli. Neutrophils are distributed predominantly in the reticular portion of the dermis, in the dermo-hypodermic junction and in the subcutaneous tissue, and can be so numerous as to make it difficult to identify the Virchow cells. Although the presence of vasculitis in these lesions is described, it is a rare feature. ${ }^{15}$

In the case of Sweet's syndrome-like type 2 reaction, the infiltration of neutrophils occurs predominantly in the papillary portion of the dermis concomitantly with pronounced edema, providing enough resemblance to Sweet's syndrome lesions itself. ${ }^{12}$ In sections stained with hematoxylin and eosin and Fite-Faraco, the pathologist should actively pursue Virchow's cells, whose identification allows the correct diagnosis.

In this case, the histopathological analysis was indicated due to the clinical setting with disseminated skin lesions and prolonged evolution. We believe that cases of Sweet's syndrome with atypical clinical manifestations or with no satisfactory therapeutic response should be studied from a histopathological point of view, since leprosy is a highly endemic disease in Brazil.

In Brazil, the treatment of choice for type 2 leprosy reaction is performed with thalidomide. Pentoxifylline is one of the alternatives in the case of contraindications of thalidomide, as well as corticosteroids. ${ }^{16}$ In our case, a woman of childbearing age, we decided to use oral corticosteroids and pentoxifylline initially, but the clinical presentation was refractory to these medications. Thus, use of thalidomide after insertion of intrauterine device and application of injectable contraceptive was proposed, according to standards of the National Health Surveillance Agency (Anvisa). ${ }^{17}$

Use of systemic corticosteroids in type 2 leprosy reaction is indicated in some cases well-established by the Ministry of Health, listed in chart 1. The authors' experience has shown that in Sweet's syndrome-like leprosy reaction, the initial therapeutic response of corticosteroid therapy is very good; however, to prevent the worsening of the reaction and allow the withdrawal of corticosteroid, the introduction of thalidomide is required. Patients with chronic forms of type 2 reaction can become dependent on corticosteroids;

CHART 1: Indications of oral corticosteroids associated with thalidomide in leprosy reaction type 2

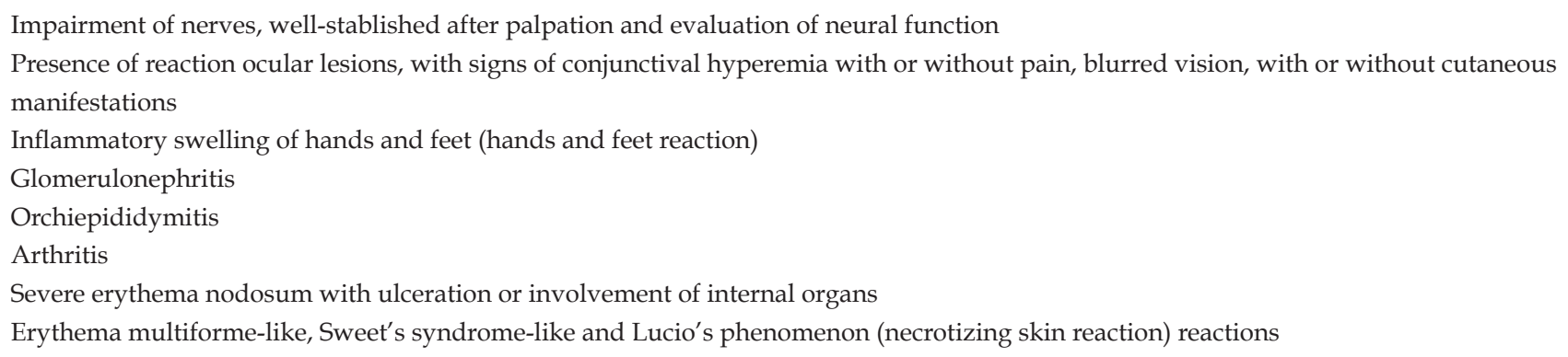

Source: Ministério da Saúde, 2010.16 
then, thalidomide is the best option to avoid adverse events of long-term therapy. ${ }^{18,19}$

The reaction conditions are the main cause of damage to the nerves and disabilities triggered by leprosy. Therefore, early diagnosis of reactions and immediate initiation of treatment are essential, in order to prevent these disabilities. ${ }^{5}$

In tropical countries, where infectious diseases such as leprosy, leishmaniasis and sporotrichosis are endemic, it is important to consider that cases similar to Sweet's syndrome may represent reaction presentations. ${ }^{20} \mathrm{~A}$ high diagnostic suspicion and a thorough clinical and laboratory evaluation are essential for the correct diagnosis. In the case of Sweet's syndrome-like leprosy reaction, the identification of vacuolated histiocytes containing bacilli in the midst of an infiltrate rich in neutrophils is of fundamental importance.

\title{
REFERENCES
}

1. Lastória JC, Abreu MA. Leprosy: review of the epidemiological, clinical, and etiopathogenic aspects - part 1. An Bras Dermatol. 2014;89:205-18.

2. Lima-Wojcik AS, Nishimori FS, Santamaria JR. Sweet's syndrome: a study of 23 cases. An Bras Dermatol. 2011;86:265-71.

3. Sweet RD. An acute febrile neutrophilic dermatoses. Br J Dermatol. 1964;76:34956.

4. Cohen PR. Sweet's Syndrome - a comprehensive review of an acute febrile neutrophilic dermatosis. Orphanet J Rare Dis. 2007;2:34.

5. Kahawita IP, Walker SL, Lockwood DNJ. Leprosy type 1 reactions and erythema nodosum leprosum. An Bras Dermatol. 2008;83:75-82.

6. Miranda AM, Antunes SL, Nery JA, Sales AM, Pereira MJ, Sarno EN. Erythema multiforme in leprosy. Mem Inst Oswaldo Cruz. 2012;107:34-42.

7. Contin LA, Delanina WFB, Barreto JA, Nogueira MES, Souza SOTB. Eritema polimorfo hansênico ulcerado "ab initio": uma apresentação atípica de hanseníase na faixa virchowiana. Hansen Int. 2008;33:35-40.

8. Kou TT, Chan HL. Severe reactional state in lepromatous leprosy simulating sweet's syndrome. Int J Dermatol. 1987;26:518-20.

9. Ramos-E-Silva M, Oliveira ML, Munhoz-da-Fontoura GH. Leprosy: uncommon presentations. Clin Dermatol. 2005;23:509-14.

10. Aires NB, Refkalefsky Loureiro W, Villela MA, Sakai Valente NY, Trindade MA. Sweet's syndrome type leprosy reaction. J Eur Acad Dermatol Venereol. 2009:23:467-9.

11. Ramesh V, Pahwa M. Some unusual type 2 reactions in leprosy. Int J Dermatol. 2010;49:172-5.

12. Heng YK, Chiam YT, Giam YC, Chong WS. Lepromatous leprosy in erythema nodosum leprosum reaction mimicking Sweet's syndrome. Int J Dermatol. 2011;50:1124-5.

13. Das T, Ghosh S, Kundu AK, Maity A. Reactional state in lepromatous leprosy simulating sweet's syndrome. J Assoc Physicians India. 2013;61:856-8.

14. Thomas M, Ponnaiya J, Emmanuel M, Richard J. Type I reaction in leprosy - a histopathological analysis. Indian J Lepr. 2013:85:1-4.

15. Sarita S, Muhammed K, Najeeba R, Rajan GN, Anza K, Binitha MP, et al. A study on histological features of lepra reactions in patients attending the Dermatology Department of the Government Medical College, Calicut, Kerala, India. Lepr Rev. 2013;84:51-64.

16. Bvsms.saude.gov.br [internet]. Brasil. Ministério da Saúde. Secretaria de Vigilância em Saúde. Departamento de Vigilância Epidemiológica. Orientações para uso: corticosteroides em hanseníase. Brasília: Editora do Ministério da Saúde; 2010. 52 p. (Série A. Normas e Manuais Técnicos) [acesso 13 out 2014]. Disponível em: http://bvsms.saude.gov.br/bvs/publicacoes/orientacoes_para_ corticosteroides hanseniase.pdf

17. Saude.gov.br [internet]. Brasil. Ministério da Saúde. Agência Nacional de Vigilância Sanitária. Resolução - RDC n 11, de 22 de março de 2011. Dispõe sobre 0 controle da substância Talidomida e do medicamento que a contenha. [acesso 13 out 2014]. Disponivel em: http://bvsms.saude.gov.br/bvs/saudelegis/ anvisa/2011/res001121 03 2011.html

18. Walker SL, Waters MF, Lockwood DN. The role of thalidomide in the management of erythema nodosum leprosum. Lepr Rev. 2007;78:197-215.

19. Projetodiretrizes.org.br [internet]. Sociedade Brasileira de Hansenologia e Sociedade Brasileira de Dermatologia. Projeto Diretrizes. Hanseníase: Episódios Reacionais. Associação Médica Brasileira e Conselho Federal de Medicina; 2003. [acesso 13 out 2014] Disponível em: http://www.projetodiretrizes.org.br/projeto diretrizes/056.pdf

20. Freitas DF, Valle AC, Cuzzi T, Brandão LG, Zancope-Oliveira RM, Galhardo MC. Sweet syndrome associated with sporotrichosis. Br J Dermatol. 2012;166(1):212-3.

\author{
MAILING ADDRESS: \\ Egon Luiz Rodrigues Daxbacher \\ Rua Sete de Setembro, 98, sala 1.103 \\ Centro \\ 20050-002 - Rio de Janeiro - RJ \\ Brazil \\ Email:egondax@gmail.com
}

How to cite this article: Chiaratti FC, Daxbacher ELR, Neumann ABF, Jeunon T. Type 2 leprosy reaction with Sweet's syndrome-like presentation. An Bras Dermatol. 2016;91(3):345-9. 